\title{
Caesarean section in second stage of labour: a commentary on principles and techniques
}

\section{Michael S. Archibong*, Wilson S. Adenikinju, Olaniyi J. Olayemi, Mariam Amuda}

Department of Obstetrics, Gynaecology and Perinatology, Obafemi Awolowo University Teaching Hospitals Complex, Ile Ife, Osun State, South-West Nigeria

Received: 19 August 2021

Accepted: 08 September 2021

\section{*Correspondence:}

Dr. Michael S. Archibong,

E-mail: beracah4@yahoo.com

Copyright: () the author(s), publisher and licensee Medip Academy. This is an open-access article distributed under the terms of the Creative Commons Attribution Non-Commercial License, which permits unrestricted non-commercial use, distribution, and reproduction in any medium, provided the original work is properly cited.

\section{ABSTRACT}

Caesarean section done at full cervical dilatation (second stage of labour) has been on the rise globally and comes with its own unique challenges and complications. This commentary highlights the peculiar challenges associated with caesarean section in second stage of labour and gives an overview on various principles to be followed and techniques to employ to reduce fetal and maternal morbidity.

Keywords: Second stage, Caesarean section, Impacted head

\section{INTRODUCTION}

Caesarean section is a common surgical procedure performed in obstetrics. Its rate has been rising over the years. The rate of rise of caesarean section can be attributed to the increase in safety of the procedure, enhanced surgical techniques, improved antibiotics, increase in number of women requesting for caesarean sections, decrease in the rate of instrumental vaginal deliveries, improved anesthesia amongst others. ${ }^{1}$

Despite the improvement of safety of caesarean sections over the years, there are still various complications arising from this procedure which may cause maternal/fetal morbidity and mortality. The stage of labour at which caesarean section is undertaken has been shown to influence the rate/risk of complication. ${ }^{2}$

Caesarean section in second stage of labour has been on the rise and poses some technical difficulties compared to antepartum or first stage caesarean section and has been shown to be associated with increased risk of adverse perinatal and maternal outcomes. Second stage caesarean section has been shown to be associated with peculiar challenges/complications such as difficult fetal delivery, uterine incision extension, postpartum hemorrhage, postpartum infection/puerperal sepsis, bladder injuries, ureteric injuries and as such, whoever undertakes a second stage caesarean section should be aware of these potential complications and also possess the requisite skill and experience to mitigate against such complications. ${ }^{1,2}$

There are certain anatomical changes that take place in advanced labour and second stage which predisposes to these complications. In second stage, the lower uterine segment is usually stretched or thinned out and "taken up" and becomes prone to laceration and tears. ${ }^{3}$

There is therefore a tendency of placing the incision too low with the attendant risk of bladder and ureteric injuries. A rare complication from this anatomic change is the accidental placement of the incision on the upper vagina to deliver the fetus; abdominal delivery without uterine incision (laparoelytrotomy). The uterine incision should therefore be slightly "higher" than it would if it were to be an antepartum or first stage caesarean section. ${ }^{3,4}$

Furthermore, due to the thinned out lower uterine segment, the lower lip of the uterine incision may sometimes retract 
into the vagina after delivery of the fetus. The posterior wall of the bladder which is usually edematous particularly in cases of prolonged and obstructed labour may be confused for the lower lip and inadvertently repaired to the uterus thereby creating an iatrogenic vesico uterine fistula and putting the patient at increased risk of secondary postpartum haemorrhage. ${ }^{5}$ Care and caution should therefore be exercised to ensure that the lower lip of the uterine incision is properly identified before repair is attempted.

Ureteric injuries following caesarean section are infrequently encountered and usually occur when there is inadvertent extension of the uterine incision into the broad ligament with subsequent attempts at securing hemostasis. Second stage caesarean sections have been shown to increase the risk of ureteric injuries. This has also been attributed to the anatomic changes in the lower uterine segment described earlier. Making a crescentic or curvilinear incision on the uterus and ensuring that the incision expansion is blunt and in the cephalad-caudad direction rather than transverse direction has been shown to reduce the risk of unintentional extension into the uterine vessels and broad ligament. ${ }^{6}$

A common challenge in second stage caesarean section is difficulty in delivering the fetus which is usually due to the fact that the head is deeply engaged or even impacted. A variety of techniques have been described in literature. One of such techniques involves delivering the fetus by reversed breech extraction (or pull method) in which the surgeon after making an incision on the lower uterine segment, directs his hand towards the fundus of the uterus in an attempt to grasp the feet of the baby and delivers the feet first followed by the buttock, trunk, shoulder and head in that order. Care must however be taken to avoid hyperextension of the neck by ensuring the traction is as gentle as possible. , $^{7}$

Alternatively, an assistant may be asked to manually displace the head cephalad until the surgeon can get below the head and delivery of other parts of the baby is completed. This technique (also known as the push method) however has been shown to be associated with unintended extensions, increased blood loss, risk of trauma to the fetus such as skull fracture, increased operation time and increased risk of postoperative infection. ${ }^{7,8}$ This manual displacement may also be done prior to commencement of the caesarean section in order to mitigate against these potential complications. ${ }^{4}$ The patient can also be placed in lithotomy position with the legs abducted to facilitate easy access to the vagina during manual displacement. ${ }^{4}$ The evidence regarding the efficacy and safety of these modifications of the push method have largely been anecdotal.

Another technique which is less commonly used due to its technicality, is the Patwardhan or 'shoulder first technique". In cases where the fetus is in occipito-anterior or transverse position, the anterior and posterior shoulders are delivered in succession, then by passing fingers through both axillae, gentle traction which is aided by fundal pressure is applied to deliver the body; the head is then subsequently lifted out of the pelvis. When the fetus is in occipito posterior position, attempt is made to grasp the corresponding foot after delivering the anterior shoulder, then with traction on the foot with fundal pressure, the buttocks, other foot and trunk are delivered. With further traction on the legs the head is subsequently delivered. ${ }^{9}$

Some devices have been invented to facilitate less traumatic delivery of the impacted head. One of such devices is the fetal displacement system or pillow which when placed into the vagina and inflated, displaces/elevates the fetal head upward, thereby making delivery of the head easier. This obviates the need for various intrauterine and vaginal maneuvers with their attendant complications. ${ }^{10}$ Another device that has been tried is the C-snorkel. This is a tubular device with multiple ventilation points at the tip. It is inserted between the fetal head and the vagina. Flow of air through the ventilation points releases the vacuum on the impacted head and reduces the force required for delivery. ${ }^{11}$ More evidence is however needed regarding the effectiveness of this devices in comparison to other conventional and cheaper methods of delivering the impacted fetal head.

Tocolytic agents have also been tried in a bid to facilitate delivery of the impacted head. The rationale for the use of tocolytic agent is that in second stage, the uterus tightly hugs the fetus. There is however no evidence to recommend the use of tocolytics as a means of facilitating delivery of the impacted head at caesarean section. Moreover, tocolytics can predispose to postpartum haemorrhage. ${ }^{7,8}$

In conclusion there is a need for more consultant's involvement and ratification regarding the decision for caesarean section to be undertaken in second stage of labour. There is also an increased need for consultant's presence in theater when the procedure is undertaken so as to equip trainees with the required competence and confidence. $^{12}$

\section{Funding: No funding sources Conflict of interest: None declared Ethical approval: Not required}

\section{REFERENCES}

1. Unterscheider J, McMenamin M, Cullinane F. Rising rates of caesarean deliveries at full cervical dilatation: a concerning trend. Eur J Obstet Gynecol Reprod Biol. 2011;157:141-4.

2. Asicioglu O, Gungorduk K, Yildirim G, Asicioglu $\mathrm{BB}$, Gungorduk OC, Ark C et al. Second-stage vs first-stage caesarean delivery: comparison of maternal and perinatal outcomes. J Obstet Gynaecol. 2014;34:598-604. 
3. Peleg D, Perlitz Y, Pansky S, Levit A, Ben-Ami M. Accidental delivery through a vaginal incision (laparoelytrotomy) during caesarean section in the second stage of labour. BJOG. 2001;108:659-60.

4. Vousden N, Cargill Z, Briley A, Tydeman G, Shennan AH. Caesarean section at full dilatation: incidence, impact and current management. Obstetric Gynaecol. 2014;16:199-205.

5. Taingson MC, Adze JA, Bature SB, Amina DM, Caleb M, Amina A et al. Post-caesarean vesicouterine fistula: Youssef's syndrome-A case report. Arch Int Surg. 2017;7:132-4.

6. Pergialiotis V, Mitsopoulou D, Biliou E, Bellos I, Karagiannis V, Papapanagiotou A et al. Cephaladcaudad versus transverse blunt expansion of the low transverse hysterotomy during cesarean delivery decreases maternal morbidity: a meta-analysis. Am J Obstet Gynecol. 2021;21:S0002-9378(21)00461-0.

7. Jeve YB, Navti OB, Konje JC. Comparison of techniques used to deliver a deeply impacted fetal head at full dilation: a systematic review and metaanalysis. BJOG. 2016;123:222.

8. Waterfall H, Grivell RM, Dodd JM. Techniques for assisting difficult delivery at caesarean section. Cochrane Database Syst Rev. 2016;1:CD004944.
9. Bhattacharya R, Ramesh AC. Cesarean Section of an Impacted Fetal Head at Full Cervical DilatationEvaluation of Patwardhan Technique. Crit Care Obst Gyne. 2020;6(4):9.

10. Randomized controlled trial of elevation of the fetal head with a fetal pillow during cesarean delivery at full cervical dilatation. Int J Gynaecol Obstet. 2016;133:178-82.

11. Clinical Innovations. Murray Utah. C-snorkel: Impacted Fetal Head Release Device by Softlift. 2012. Available

at: http://www.clinicalinnovations.com/products/c_snor kel. Accessed on 20 April 2020.

12. Olah KS. Reversal of the decision for caesarean section in the second stage of labour on the basis of consultant vaginal assessment. J Obstet Gynaecol. 2005;25:115-6.

Cite this article as: Archibong MS, Adenikinju WS, Olayemi OJ, Amuda M. Caesarean section in second stage of labour: a commentary on principles and techniques. Int J Reprod Contracept Obstet Gynecol 2021;10:4038-40. 